\title{
CAPITULO 8 GESTÃO DE RESÍDUOS SÓLIDOS URBANOS: UMA ANÁLISE DA VIABILIDADE ECONÔMICA DA RECICLAGEM EM CRICIÚMA - SC
}

DOI: http://dx.doi.org/10.18616/pgt08

Gláucia Cardoso de Souza-Dal Bó Amanda Bellettini Munari Viviane Kraieski de Assunção Adriano Michael Bernardin

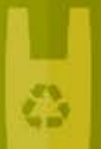




\section{INTRODUÇÃO}

A geração de resíduos sólidos é problema inerente à vida em sociedade, diretamente atrelado ao aumento da população e ao processo de urbanização (JARDIM et al., 2000) e que se agrava na medida em que há uma produção extremamente diversa de bens e componentes de reduzida vida útil. Essa dinâmica recorrente de consumo e descarte, devidamente alimentada por um modelo que privilegia o esgotamento dos recursos naturais e o comprometimento da qualidade socioambiental, implica a necessidade de locais ambientalmente seguros de disposição final, e mais do que isso, a busca por alternativas de valorização e de otimização das vias de reciclagem.

Conceitualmente, resíduos sólidos constituem-se de restos, materiais, substâncias, objetos ou bens descartados pelas inúmeras atividades humanas e caracterizam-se, principalmente, pela possibilidade de reutilização ou valorização enquanto subproduto ou matéria-prima secundária (CONSONI; PERES; CASTRO, 2000; LIMA, 2001; PHILIPPI Jr., AGUIAR, 2005). Os rejeitos, entretanto, caracterizam-se pela inexistência ou mesmo pela inviabilidade econômica em relação às tecnologias capazes de reciclá-los e, por isso, não apresentam outra possibilidade que não a disposição final ambientalmente adequada (BRASIL, 2010).

No que se refere à classificação, os resíduos podem ser categorizados de diferentes maneiras: acordo com as fontes geradoras; conforme a composição física (gravimétrica) ou química; em função de suas propriedades; ou, mais usualmente, conforme a periculosidade (MARTINHO; GONÇALVES, 2001). Resíduos sólidos urbanos (RSU) compõem-se de resíduos classificados quanto à origem, em domicliar e público, e são originários de residências domésticas urbanas e da limpeza de vias e logradouros públicos e demais serviços de poda e varrição (BRASIL, 2010).

Legalmente, a problemática dos resíduos no Brasil está amparada pela Lei n. 12.305 (BRASIL, 2010). Entre os seus princípios, constam a responsabilidade compartilhada pelo ciclo de vida dos produtos e a integração dos catadores de materiais recicláveis em tais ações. Além disso, 
ela incentiva a indústria da reciclagem e a gestão integrada de resíduos sólidos e cita, como instrumentos, os planos de resíduos, a coleta seletiva e a criação e desenvolvimento de cooperativas e associações de catadores, com vistas à inclusão social desses sujeitos.

A reciclagem está atrelada à economia de matérias-primas e de energia, além de contribuir para que os aterros tenham uma vida útil mais prolongada. É possível recuperar, direta ou indiretamente, componentes passíveis de serem utilizados na manufatura de outros produtos (VILHENA; ALMEIDA, 2000; MONTEIRO et al., 2001; MONTEIRO, 2001).

Embora a Política Nacional de Resíduos Sólidos tenha normatizado explicitamente a responsabilidade pela gestão de resíduos sólidos, exigindo a elaboração dos planos por parte dos estados e municípios e a extinção dos lixões como alternativa de disposição final, inclusive, com sanções àqueles que não cumprissem os prazos, a efetividade dessas mudanças não são conseguidas em um curto espaço de tempo, dada a complexidade dessa problemática e a realidade de muitos municípios.

A implementação ou otimização de práticas de coleta seletiva e reciclagem, com aproveitamento expressivo da fração reciclável e consequente geração de emprego e renda para as associações e cooperativas, é um exercício contínuo de cooperação e colaboração de vários agentes da sociedade e que depende fundamentalmente de recursos operacionais e financeiros para ser posta em prática e, sobretudo, para transpor os conflitos na manutenção de uma atividade tão nobre e necessária para a sociedade.

No tocante às políticas públicas sociais e econômicas voltadas para os catadores, além da PNRS, há outros marcos legais que amparam essa classe trabalhadora - reconhecida enquanto categoria profissional pelo Ministério do Trabalho e Emprego no ano de 2002 - e que contribuem para o reconhecimento e empoderamento do associativismo e do cooperativismo. Em 2006, o Decreto n. 5.940 instituiu a coleta seletiva em órgãos públicos federais com destinação dos materiais recicláveis às associações e cooperativas de catadores. A Lei de Saneamento Básico, n. 11.445 de 2007, fomenta a contratação de associações e cooperativas de catadores, pelas prefeituras, com dispensa de licitação para o serviço de 
coleta seletiva. Em 2010, foi deliberado o Decreto Pró-Catador, como resultado de um esforço do Governo Federal, que fez menção à atuação de um Comitê Interministerial para Inclusão Social e Econômica dos Catadores de Materiais Reutilizáveis e Recicláveis (ASSUNÇÃO et al., 2017).

Diante do exposto e das dificuldades inerentes à operacionalização dos sistemas de coleta seletiva, as quais comprometem a sua finalidade no tocante à valorização efetiva dos resíduos recicláveis e ao trabalho das organizações de catadores, a presente pesquisa se propôs ao diagnóstico temporal da gestão de resíduos sólidos urbanos nos cenários nacional e regional (sul) e ao estudo da viabilidade econômica da reciclagem aplicado à Criciúma, empregando o software VERDES ${ }^{\circledR}$. A partir dos dados contidos no plano municipal de gestão de resíduos (PMGIRS, 2016) e dos resultados provenientes do software, pôde-se confrontar a realidade experenciada no plano com a real potencialidade de valorização dos materiais recicláveis descartados no município em análise.

Nesse ínterim, a principal contribuição deste estudo, que oferece subsídios para a discussão e aprimoramento da gestão de resíduos sólidos em todas as esferas (nacional, regional e municipal), estende-se à melhoria da qualidade do ambiente e de vida dos habitantes e, sobretudo, dos catadores atuantes em um segmento tão importante para a sociedade e, ao mesmo tempo, tão desprovido de reconhecimento e apoio dos poderes públicos.

\section{PROCEDIMENTOS METODOLÓGICOS}

\section{UNIDADE DE ANÁLISE}

Definiram-se como locus de problematização, no tocante à geração, coleta, destinação e disposição dos resíduos sólidos urbanos, os cenários nacionais, regional (sul) e municipal (Criciúma, SC). O estudo da viabilidade da reciclagem foi aplicado particularmente à cidade de Criciúma. 
A Tabela 1 fornece a caracterização em termos de população e área ocupada, e a Figura 1 indica a abrangência da pesquisa em relação às unidades de análise.

Tabela 1 - Caracterização das unidades de estudo em relação à população e área

\begin{tabular}{lccc}
\hline & Pop. total (hab.) & Pop. urbana (\%) & Área $\mathbf{( k m}^{\mathbf{2}}$ ) \\
\hline Brasil & 207.874 .059 & 78 & 8.514 .876 \\
Região Sul & 29.439 .773 & 79 & $576.783,781$ \\
Criciúma & 209.153 & 98 & 235,701 \\
\hline
\end{tabular}

Fonte: SEBRAE, 2013; IBGE, 2016; PMGIRS, 2016.

Figura 1 - Localização da abrangência da pesquisa em relação às unidades de análise

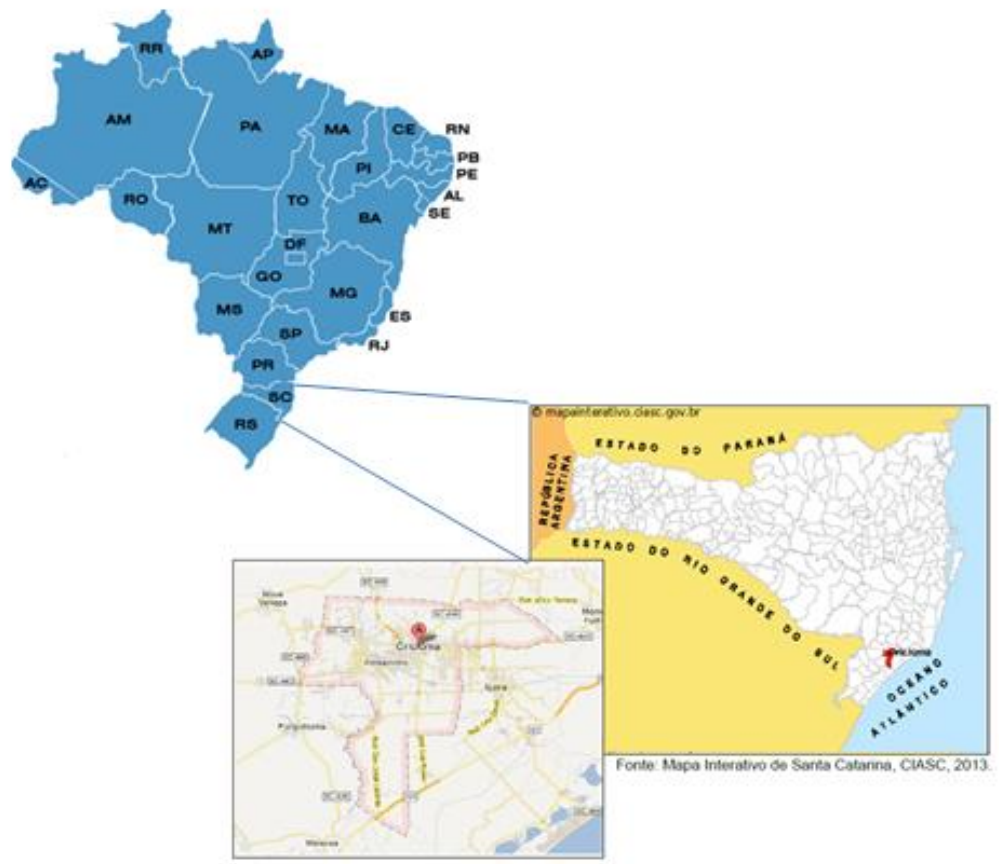

Fonte: Adaptada de SEBRAE/SC, 2013, p. 11; IBGE, 2017. 


\section{CARACTERIZAÇÃO DA PESQUISA}

No que se refere à caracterização da pesquisa, ela se insere em uma abordagem quanti-qualitativa. O cenário da gestão de resíduos foi descrito e analisado e, ao final, foram tecidas considerações a partir da interpretação dos dados e informações obtidos (CRESWEL, 2007). No que se refere ao objetivo, a pesquisa é norteada pela perspectiva exploratória. Esse tipo de pesquisa dedica-se ao aprimoramento de ideias e à descoberta de intuições. Além de envolver levantamento bibliográfico, entrevistas e análise de exemplos (GIL, 2007).

Fez-se uso da coleta documental e de entrevistas, via contato telefônico, com as duas unidades de triagem existentes no município de Criciúma, com a finalidade de atualizar alguns dos dados contidos no plano, sobretudo relativos à comercialização de recicláveis. Os documentos analisados foram os seguintes:

a. Plano Nacional de Resíduos Sólidos (PNRS, 2012).

b. Panorama dos Resíduos Sólidos no Brasil 2015 (ABRELPE, 2015).

c. Diagnóstico do Manejo de Resíduos Sólidos Urbanos (SNIS, 2015).

d. Plano Municipal de Gestão Integrada de Resíduos Sólidos de Criciúma (PMGIRSC, 2016).

Os resultados sobre a viabilidade da reciclagem no município foram obtidos por meio do software VERDES ${ }^{\circledR 1}$, cujo emprego permitiu simular os ganhos mercadológicos com a reciclagem no município. O software foi desenvolvido pelo Prof. Dr. Márcio Conceição Magera, na ocasião do seu pós-doutoramento pela UNICAMP, e foi lançado no ano de 2007.

A metodologia de cálculo, absolutamente fundamentada em dados científicos, tem como princípio a matemática mercadológica dos recursos

1 VERDES ${ }^{\circledR}$ : VIABILIDADE ECONÔMICA DA RECICLAGEM DE RESÍDUOS SÓLIDOS. O programa fornece três conjuntos de dados: análise macroambiental, análise mercadológica e balanço ambiental. Esta pesquisa fará a análise somente da análise mercadológica. 
naturais utilizados na composição de alguns materiais recicláveis (lata de alumínio, lata de aço, plástico, papel e papelão). São considerados os preços de mercado associados aos serviços públicos e privados de transformação desses recursos até chegar ao consumidor final, nos quais se inserem custos atrelados à coleta e aos processos de produção e reciclagem (MAGERA, 2007).

A Tabela 2 apresenta os dados de entrada, considerando os valores sugeridos pelo programa e os valores que foram de fato utilizados e atualizados para o cálculo da viabilidade em Criciúma, incluindo as fontes de consulta.

Tabela 2 - Dados de entrada do software VERDES ${ }^{\circledR}$ e as fontes de consulta

\begin{tabular}{|c|c|c|c|}
\hline \multicolumn{4}{|c|}{ Dados iniciais } \\
\hline Indicador & $\begin{array}{c}\text { Valor } \\
\text { sugerido }\end{array}$ & $\begin{array}{c}\text { Valor } \\
\text { utilizado }\end{array}$ & Fonte \\
\hline № de habitantes & $*$ & 209.153 & (IBGE, 2016) \\
\hline Valor salário mínimo (R\$̦) & $*$ & 937,00 & (BRASIL, 2016) \\
\hline Cotação do dólar (US\$̦) & * & 3,17 & (BCB, 2017) \\
\hline Geração per capita (kg/hab./dia) & 0,7 & 0,66 & (PMGIRSC, 2016) \\
\hline Custo reciclagem (R\$/ton.) & 792,5 & 792,5 & (VERDES $\left.{ }^{\oplus}\right)$ \\
\hline Custo evitado com coleta (R\$̦/ton.) & 190,2 & 190,2 & (VERDES $\left.{ }^{\circledR}\right)$ \\
\hline \multicolumn{4}{|c|}{ Preço de mercado dos produtos reciclados (R\$/ton.) } \\
\hline Latas de alumínio** & 5706 & 3200 & (PMGIRSC, 2016) \\
\hline Vidro & 285,3 & 30 & (PMGIRSC, 2016) \\
\hline \multicolumn{4}{|l|}{ Continuação } \\
\hline Papel*** & 475,5 & 298.75 & (PMGIRSC, 2016) \\
\hline Plástico*** & 1109,5 & 972 & (PMGIRSC, 2016) \\
\hline Latas de aço** & 475,5 & 100 & (PMGIRSC, 2016) \\
\hline \multicolumn{4}{|c|}{ Índice de reciclagem dos resíduos sólidos (\%) } \\
\hline Latas de alumínio & 95 & 98 & (ABRELPE, 2015) \\
\hline Vidro & 46 & 46 & (ABIVIDRO, 2013) \\
\hline Papel & 45 & 63 & (ABRELPE, 2015) \\
\hline Plástico & 32 & 51 & (ABRELPE/ABPET, 2015) \\
\hline Latas de aço & 47 & 47 & (ABEAÇO, 2013) \\
\hline \multicolumn{4}{|c|}{ Composição dos resíduos } \\
\hline Latas de alumínio (unid./mês) & 4,5 & 11 & (PMGIRSC, 2016) \\
\hline Vidro (\%) & 4 & 8 & (PMGIRSC, 2016) \\
\hline Papel (\%) & 26 & 9 & (PMGIRSC, 2016) \\
\hline Plástico (\%) & 7 & 20 & (PMGIRSC, 2016) \\
\hline Latas de aço (kg/ano) & 4 & 3 & (PMGIRSC, 2016) \\
\hline Orgânico (\%) & 49 & 36 & (PMGIRSC, 2016) \\
\hline
\end{tabular}

*Não há dados sugeridos para esses indicadores.

**Esses valores foram atualizados via contato telefônico com uma das unidades de triagem do município, a CTMAR.

***Calculou-se uma média para os materiais papel e plástico.

Fonte: Elaborada pelos autores, 2017. 
É importante destacar que o próprio software sugere o emprego de uma série de dados quando esses, por algum motivo, não podem ser obtidos ou são inacessíveis. No entanto, de posse do plano de gestão municipal de Criciúma (PMGIRSC, 2016), foi possível utilizar indicadores que fidelizam a situação do município, como a composição gravimétrica e o preço de comercialização dos recicláveis. Consequentemente, são fornecidos resultados mais próximos da realidade e a margem de erro é reduzida. A margem de acerto é superior a $80 \%$.

\section{RESULTADOS E DISCUSSÃO}

O Plano Nacional de Resíduos Sólidos (PNRS, 2012) fornece dados relativos aos anos de 2002 e 2008, originários de fontes diversas, sobretudo do IBGE. A partir dos dados divulgados no panorama da ABRELPE (2015) e do diagnóstico de manejo de resíduos sólidos do Ministério das Cidades (SNIS, 2015), esses valores puderam ser atualizados e a sua evolução, analisada. A pesquisa da ABRELPE foi realizada com 400 municípios e o diagnóstico do SNIS contou com a participação de $3.520(63,2 \%)$ cidades brasileiras, ambos relacionados ao ano de 2015 . A evolução da quantidade gerada de RSU em escala nacional e regional (Sul) pode ser vista no Gráfico 1.

Gráfico 1 - Evolução da estimativa da quantidade de resíduos sólidos domiciliares e/ou públicos coletada (ton./dia) para o cenário nacional e regional (Sul)

\section{Geração de RSU (mil ton./dia)}

घBrasil $\square$ Região sul

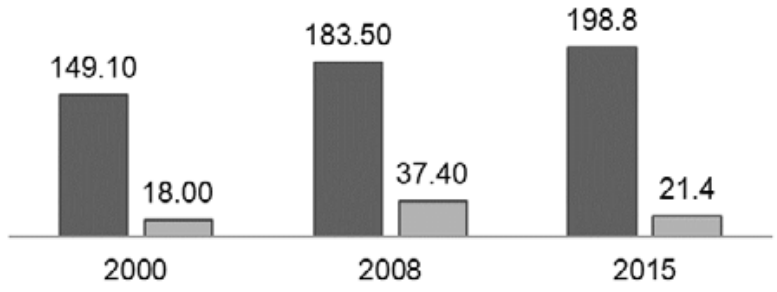

Fonte: Adaptado de PNRS, 2012, e ABRELPE, 2015. 
De acordo com dados do SNIS (2015), a geração de RSU no país é na ordem de 171,3 mil ton./dia, valor inferior ao encontrado no panorama da ABRELPE (2015). Não há estimativa da geração para a região Sul no documento do SNIS (2015). Contrariando a tendência de aumento na geração de resíduos no país observada entre os anos de 2000 e 2015, há uma diminuição de 16 mil ton./dia no último período analisado (2008-2015) na região Sul, o que representa uma queda de $42,78 \%$. A evolução da geração de RSU per capita (kg/hab./dia) pode ser observada no Gráfico 2.

Gráfico 2 - Evolução da estimativa de geração per capita de RSU, no panorama nacional e regional (sul)

Geração per capita (kg/hab./dia)

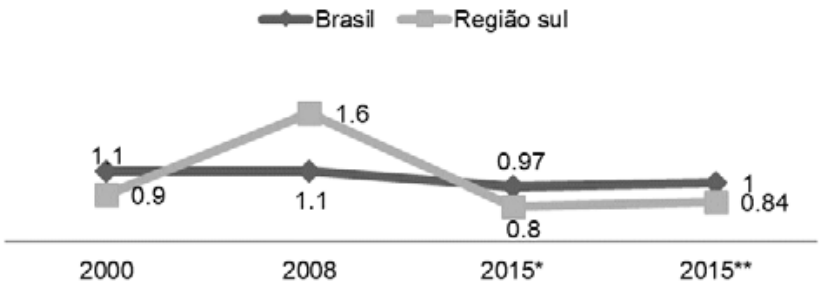

Fonte: Adaptado de PNRS, 2012, ABRELPE, 2015 e SNIS 2015.

*Dados da ABRELPE e **Dados do SNIS relacionados à população urbana.

Observa-se que, entre os anos 2000 e 2008, a geração per capita de RSU na região Sul superava os índices nacionais em 0,5 kg/ hab./dia. Entre 2008 e 2015, a quantidade de RSU gerados per capita, na mesma região, teria caído pela metade: de $1,6 \mathrm{~kg} / \mathrm{hab} . /$ dia para $0,8 \mathrm{~kg} /$ hab./dia, tornando-se inferior ao panorama nacional (entre 0,97 e $1 \mathrm{~kg} /$ hab./dia) e mais próximo ao estimado para o ano 2000 (0,9kg/hab./dia).

No que diz respeito à taxa de cobertura da coleta regular de resíduos sólidos, o plano nacional aponta $98 \%$ em relação aos domicílios situados em área urbana no ano de 2009 (PNRS, 2012). Dados do SNIS (2015) sinalizam praticamente o mesmo índice para a população urbana em 2015: 98,6\%. Quanto à totalidade da população, consta no panorama da ABRELPE uma taxa de cobertura de coleta de $90,8 \%$, enquanto o SNIS (2015) informa 92,7\%. 
No que se refere à coleta seletiva, entre os anos de 2000 e 2008, somente 994 (18\%) municípios desenvolviam programas voltados para o recolhimento diferenciado de recicláveis (PNRS, 2012). Em 2015, as projeções da ABRELPE (2015) sinalizaram que aproximadamente $70 \%$ das cidades possuíam alguma iniciativa voltada para a coleta seletiva. Em contrapartida, da totalidade de municípios que participaram da pesquisa do SNIS (2015), somente 37,5\% declararam desenvolver ações nesse sentido. O SNIS (2015) apresenta, ainda, a massa de RSU destinado à coleta seletiva em 2015: cerca de 1,76 milhões de ton./ano em relação ao país; e 802,6 ton./ano na região Sul. No que se refere aos agentes executores do serviço de coleta seletiva, o Gráfico 3 ilustra a distribuição em relação às fontes executoras.

Os dados indicam que, no país, as empresas contratadas pelas prefeituras são as principais responsáveis pela coleta seletiva, seguidas pelos catadores e por órgãos municipais. Na região Sul, há uma maior presença da iniciativa privada e da prefeitura na coleta de materiais recicláveis do que a média nacional. Também em relação ao cenário nacional, há, na mesma região, uma participação significativamente menor de catadores com apoio do poder público municipal na coleta seletiva.

Gráfico 3 - Distribuição percentual da massa de RSU recolhida pela coleta seletiva segundo agente executor, em escala nacional e regional (Sul)

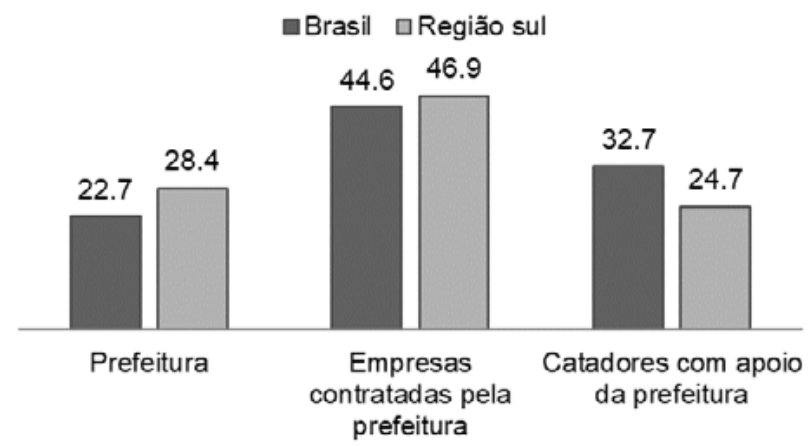

Fonte: Adaptado pelos autores (SNIS, 2015). 
Esses números sugerem a necessidade de fomento às iniciativas de empreendimentos solidários de catadores no país e, especialmente, na região Sul, como forma de implementação das orientações da Política Nacional de Resíduos Sólidos (BRASIL, 2010), que visam à inclusão social desses trabalhadores.

O plano nacional sinaliza que foi reciclado no país, em 2008, um total de 15.096,7 toneladas de resíduos, dos quais somente 579,2 ton./ ano provinham de programas oficiais de coleta seletiva (PNRS, 2012). O SNIS (2015) refere-se à massa recuperada de recicláveis secos em 2015: 863,3 mil ton./ano no país; e 304,3 ton./ano na região Sul.

Ainda no PNRS (2012), há dados relativos à destinação final nos anos de 2002 e 2008 de RSU, entretanto locais de disposição final, tais como lixões e aterros, também foram considerados como alternativas de destinação. As unidades de triagem para a reciclagem e compostagem totalizaram somente $6 \%$ das alternativas em 2002 e 2,2\% em 2008. O SNIS (2015) apresenta o número de unidades de processamento, nas quais também se inserem tanto alternativas de destinação quanto de disposição final, e informa a massa total de resíduos recebida por essas unidades. Estima-se que as 3.859 unidades existentes no país tenham recebido cerca de 78 milhões de toneladas de resíduos em 2015. Na região Sul, são 698 unidades que receberam cerca de 8,9 milhões de toneladas. Da totalidade de unidades no país, 846 são de triagem e 278 se situam na região Sul. No Brasil, a massa estimada recebida pelas unidades de triagem é de aproximadamente 2,5 milhões de ton./ano de resíduos, e na região Sul, 819 mil ton./ano.

No tocante à disposição final, dados da PNRS (2012) relativos a 2002 e 2008 e da ABRELPE (2015) permitem identificar a quantidade encaminhada para disposição final. Estima-se, segundo o panorama, que $58 \%$ dos RSU coletados anualmente no Brasil sejam destinados de forma correta. O Gráfico 4 ilustra a evolução da quantidade estimada depositada no país, em relação às alternativas de disposição adotadas. 
Gráfico 4 - Evolução da estimativa da quantidade (ton./dia) de RSU encaminhados para disposição final no país

\section{Disposição final no Brasil (mil ton./dia)}

$$
\text { =Aterro sanitário }=\text { Aterro controlado = Lixão }
$$

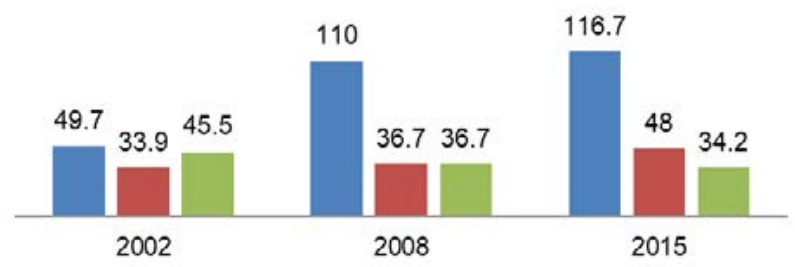

Fonte: Adaptado de PNRS, 2012, e ABRELPE, 2015.

Essas estimativas sugerem um crescimento na quantidade de RSU depositada em aterros sanitários e em aterros controlados no país, acompanhado de uma diminuição na disposição em lixões no mesmo período. Destaca-se, no entanto, que a quantidade depositada em lixões no país teve uma diminuição de apenas 6,81\% entre 2008 e 2015, período em que entrou em vigência a Política Nacional de Resíduos Sólidos. Essa queda é inferior à apresentada no período anterior, de 2002 a 2008, que aponta uma diminuição de 19,34\% na quantidade de RSU depositada em lixões. O Gráfico 5 ilustra a evolução no número de unidades de disposição final no país.

Gráfico 5 - Evolução do número de unidades de disposição final no país

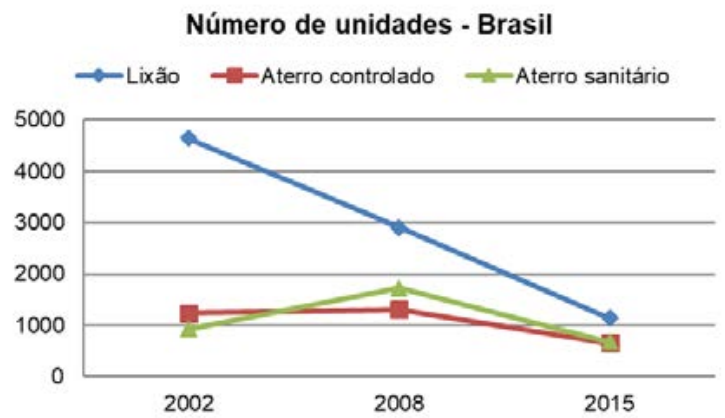

Fonte: Adaptado de PNRS, 2012, e SNIS, 2015. 
Dados de 2015 do SNIS informam que há no país 1.140 lixões, 654 aterros controlados e 679 aterros sanitários. Logo, o número de lixões como forma de disposição final no país reduziu consideravelmente ao longo dos anos. Do mesmo modo, os aterros controlados foram reduzidos pela metade entre 2002 e 2015. Percebeu-se um aumento no número de aterros sanitários, de 2002 a 2008, entretanto essa ascensão não se manteve em relação ao ano de 2015.

Da totalidade de resíduos sólidos urbanos coletados no país, a região Sul contribui com $10,7 \%$ do cenário nacional. Os índices de cobertura da coleta de resíduos considerando a totalidade da população, em relação aos documentos analisados, são equiparados: 93\% (SNIS, 2015) e 94,3\% (ABRELPE, 2015). Considerando a população urbana da região Sul atendida pelo serviço de coleta, o índice apresentado pelo SNIS (2015) é bastante elevado: 99,4\%.

Quanto à coleta seletiva, cerca de $90 \%$ dos municípios da região Sul apresentam alguma iniciativa ligada à recolha diferenciada de recicláveis (ABRELPE, 2015). O percentual registrado pelo SNIS (2015) é relativamente inferior ao da ABRELPE (2015): 54,8\% dos municípios da região Sul se declararam "com coleta seletiva" na pesquisa. Considerando a coleta seletiva exclusivamente na modalidade porta a porta, seja ela realizada pela prefeitura, por empresa contratada ou por organização de catadores, esse percentual cai para 49,1\%.

De acordo com dados da ABRELPE (2015) sobre a disposição final de RSU na região Sul, 70,9\% da totalidade de resíduos coletados são dispostos em aterros sanitários, 18,3\% em aterros controlados e 10,8\% em lixões. O Gráfico 6 ilustra a evolução da quantidade estimada depositada na região Sul, em relação às alternativas de disposição final. 
Gráfico 6 - Evolução da estimativa da quantidade (ton./dia) de RSU encaminhados para disposição final na região Sul Disposição final na região Sul (mil ton./dia)

=Aterro sanitário $=$ Aterro controlado $=$ Lixão

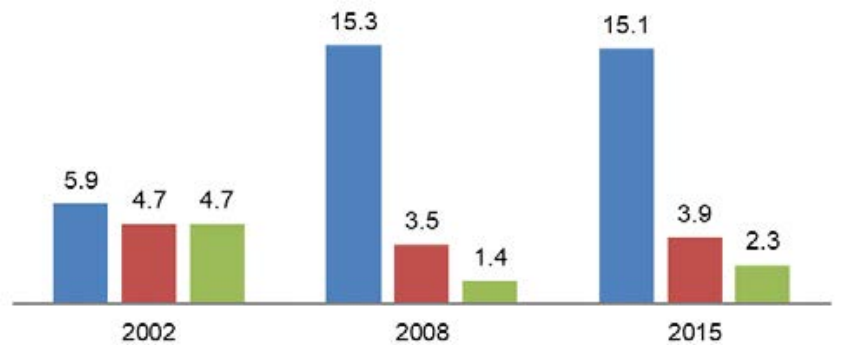

Fonte: Adaptado de PNRS, 2012, e ABRELPE, 2015.

Os dados apontam um aumento na disposição de RSU em aterros sanitários na região Sul entre 2002 e 2008, e uma manutenção desses números entre 2008 e 2015. Enquanto no primeiro período analisado há uma significativa queda de $70,2 \%$ no montante depositado em lixões, no período seguinte, essa quantidade aumenta em 39,1\%. Esses números representam um retrocesso em relação ao cenário nacional, que indica um crescimento constante nas quantidades de RSU depositadas em aterros sanitários e controlados, além de uma diminuição, no mesmo período, do montante encaminhado para os lixões. O Gráfico 7 apresenta a evolução do número de unidades de disposição final na região Sul.

Gráfico 7 - Evolução do número de unidades de disposição final na região Sul

Número de unidades - região Sul

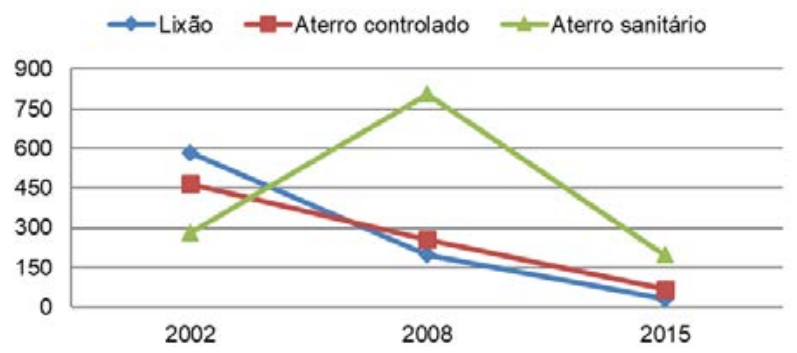

Fonte: Adaptado de PNRS, 2012, e SNIS, 2015. 
Seguindo a tendência nacional, o número de lixões e aterros controlados reduziu ao longo dos anos. Observou-se um aumento no número de aterros sanitários, de 2002 a 2008, no entanto essa elevação não se manteve no ano de 2015 , assim como no cenário nacional.

\section{GESTÃO DE RSU EM CRICIÚMA: ANÁLISE DA VIABILIDADE DA RECICLAGEM POR MEIO DO SOFTWARE VERDES $®$}

A população de Criciúma está estimada em 209.153 pessoas, distribuídas em uma área de $235,701 \mathrm{~km}^{2}$ (IBGE, 2016). Considerando o período compreendido entre os anos de 2002 e 2013, verificou-se que a geração per capita de um habitante criciumense varia entre 0,48 e 0,73 $\mathrm{kg} / \mathrm{dia}$ de resíduos. O valor mais atualizado é do ano de 2014: 0,66 kg/ hab./dia (PMGIRS, 2016). O Gráfico 8 permite analisar a evolução da quantidade de resíduos coletada no município (2002-2013).

Os dados mostram que a geração de RSU no município não variou de forma expressiva ao longo de 2002 e 2011, com relativo ápice nos anos de 2004 e 2006, cuja geração ficou próxima das 40 mil ton./dia. A partir de 2011, no entanto há um crescimento em relação aos anos anteriores, que culmina no ano de 2013 com a produção de 51,9 mil ton./ano.

Gráfico 8 - Evolução da estimativa da quantidade de resíduos sólidos coletados no município de Criciúma e encaminhados para disposição final

Quantidade encaminhada para disposição final (mil ton./ano)

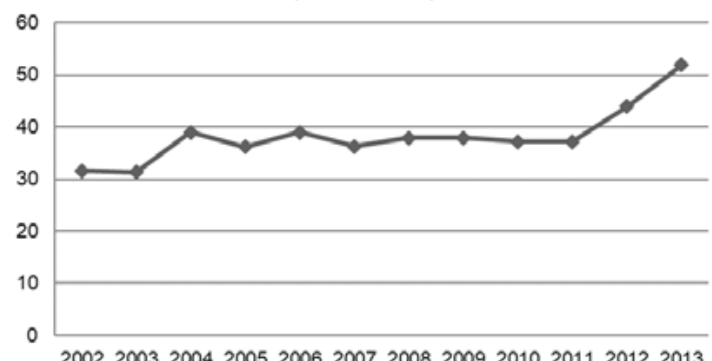

Fonte: Adaptado de PMGIRS, 2016. 
A partir da geração per capita de 2014 e da população estimada em 2016 (PMGIRS, 2016; IBGE, 2016), o software VERDES ${ }^{\circledR}$ forneceu a geração per capita mensal e anual e, ainda, a totalidade de resíduos gerados (Tabela 3).

Tabela 3 - Geração per capita e total de resíduos produzidos

\begin{tabular}{ccc}
\hline & Geração per capita $\mathbf{( k g )}$ & Total de resíduos gerados (ton.) \\
\hline Dia & 0,6 & 138 \\
Mês & 19 & 4.141 \\
Ano & 237 & 49.694 \\
\hline
\end{tabular}

Fonte: Elaborada pelas autoras, a partir do software VERDES ${ }^{\circledR}, 2007$.

Anualmente, um habitante criciumense gera, em média, 237 $\mathrm{kg}$ de resíduos, os quais totalizam aproximadamente 49,7 mil ton. em relação à população total; valor bastante próximo ao encontrado no plano municipal, sobretudo no ano de 2013 (Gráfico 7).

O município dispõe de dois tipos de coleta de resíduos: a regular e a seletiva. Adverte-se, entretanto, que a quantidade recolhida pela coleta seletiva, embora tenha se elevado, é muito inferior ao que é recolhido pela coleta convencional (Gráfico 9).

Gráfico 9 - Evolução da estimativa da quantidade de resíduos sólidos coletados no município de Criciúma conforme o tipo de coleta

Quantidade coletada por tipo (mil ton./ano)

- Coleta seletiva $\quad$ Coleta convencional

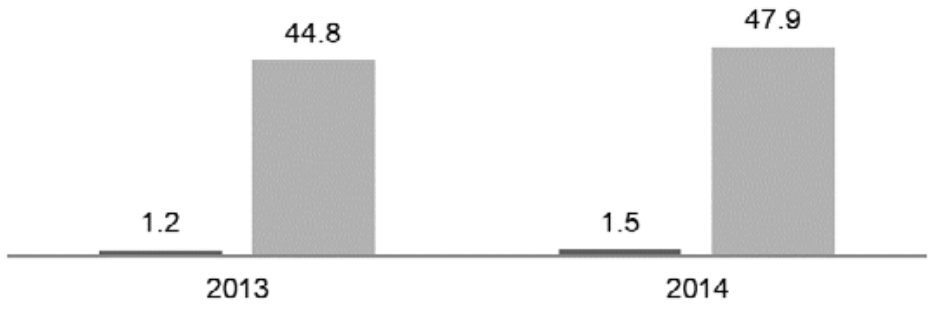

Fonte: Adaptado de PMGIRS, 2016. 
O material reciclável seco é encaminhado para duas unidades de triagem: a ACRICA e a CTMAR. As duas unidades triam juntas cerca de 132 ton./mês de material potencialmente reciclável, dos quais conseguem comercializar 70,6 toneladas: ou seja, 54\% do material que chegam às unidades são convertidos em receita para os associados e cooperados; muito material deixa de ser valorizado. A Tabela 4 fornece características importantes para analisar o funcionamento das unidades de triagem.

Tabela 4 - Caracterização das unidades de triagem de Criciúma em relação à quantidade triada, produção de rejeitos e comercialização

\begin{tabular}{lcc}
\hline & ACRICA & CTMAR \\
\hline Quantidade triada (ton./dia) & 2 & 4 \\
Produção de rejeitos (bags) & 4 & 30 \\
Média mensal comercializada de material (kg/mês) & $25.265,36$ & $45.262,01$ \\
Total comercializado (R\$/mês) & $12.255,21$ & $29.954,45$ \\
№ de colaboradores & 22 & 28 \\
Valor médio da tonelada comercializada (R\$̦/Ton.) & 485,06 & 661,80 \\
\hline
\end{tabular}

Fonte: Adaptado de PMGIRS, 2016.

Em contrapartida, com base no software VERDES ${ }^{\circledR}$, a Tabela 5 apresenta a mensuração dos ganhos possíveis a partir da comercialização dos principais produtos recicláveis gerados, considerando a composição gravimétrica do município, a quantidade de resíduos gerada pela população e a média de preço de venda dos materiais recicláveis pela ACRICA e CTMAR.

Tabela 5 - Quantidade de produtos recicláveis presentes nos resíduos gerados pela população de Criciúma e a econômica obtida com a reciclagem

\begin{tabular}{lcc}
\hline \multicolumn{1}{c}{ Produto } & Quantidade (ton./ano) & Economia obtida (R\$/ano) \\
\hline Latas de alumínio & 430 & $1.378 .201,00$ \\
Vidro & 3.975 & $119.267,00$ \\
Papel/papelão & 4.472 & $1.336 .167,00$ \\
Plástico & 9.938 & $9.660 .659,00$ \\
Latas de aço & 627 & $62.745,00$ \\
\hline Total & $\mathbf{1 9 . 4 4 5}$ ton./ano & $\mathbf{R} \mathbf{1 2 . 5 5 7 . 0 4 2 , 0 0 / a n o}$ \\
\hline
\end{tabular}

Fonte: Adaptada de PMGIRS, 2016. 
Os dados relativos ao cenário mercadológico permitem inferir que são geradas pela população de Criciúma cerca de 53,3 ton./dia de resíduos potencialmente recicláveis. O retorno econômico obtido com a comercialização desse montante, considerando que a totalidade desse material chegasse às unidades de triagem e que não houvesse perdas ou geração de rejeitos, seria na ordem de $\mathrm{R} \$ 12,6$ milhões/ano.

Confrontando a simulação do software com a realidade municipal, verificou-se que a quantidade de material recolhido pela coleta seletiva em 2014 foi de 4,2 ton./dia (Gráfico 9) e que a quantidade triada pelas unidades, com base em dados mais atualizados do plano, é de 6 ton./dia (Tabela 4). Portanto, o software mostrou que são geradas 53,3 ton./dia de recicláveis pela população e, desse montante, somente 6 ton./dia (12\%) estão sendo destinadas para as unidades de triagem.

Do mesmo modo, comparando o retorno econômico com a venda dos materiais, a ACRICA possui uma receita anual de cerca de $R \$$ 147 mil e a CTMAR de aproximadamente $\mathrm{R} \$ 360$ mil. Ainda que a eficiência máxima de destinação não seja alcançada, a receita das unidades está muito abaixo do que poderia ser; representa somente $1,18 \%$ para a ACRICA e 2,9\% para a CTMAR dos 12,6 milhões calculados pelo software. $O$ valor médio da tonelada comercializada fornecido pelo programa foi de $\mathrm{R} \$ 645$, superior ao valor obtido pela ACRICA e muito próximo do montante conseguido pela CTMAR.

É importante ressaltar a situação de precariedade de ambos os empreendimentos, cujos problemas caracterizam-se por deficiências de ordem institucional e de gestão ambiental e administrativa. Tampouco há segurança jurídica em relação aos locais de trabalho (ASSUNÇÃO et al, 2017).

Em síntese, não há apoio do poder público municipal, nem qualquer sinal de políticas de inclusão dessa classe trabalhadora; muito pelo contrário: observa-se um ciclo perverso e contínuo de exclusão social (MIURA; SAWAIA, 2013). 


\section{CONSIDERAÇÕES FINAIS}

Alguns dos documentos oficiais consultados se referem igualmente aos termos destinação e disposição e dificultam a real compreensão do cenário atual de valorização dos resíduos sólidos. Ainda que o número de lixões tenha diminuído e que as exigências legais tenham relativamente conduzido à disposição ambientalmente segura em aterros sanitários, a fração destinada às unidades de triagem, tanto no cenário nacional quanto regional, representa um valor pequeno diante da totalidade que é gerada e coletada. Da totalidade de resíduos encaminhados para unidades de processamento, somente $3,2 \%$ seguem para unidade de triagem, por ano. Na região Sul, esse percentual é de 9,2\%.

Quanto à viabilidade de reciclagem em Criciúma, constatou-se que a situação não difere dos panoramas nacional e estadual e que a quantidade de resíduos triada e comercializada, assim como a receita obtida pelos associados e cooperados das unidades de triagem do município, poderia ser potencialmente mais elevada. Essa observação pode ser afirmada pelos resultados obtidos no software, confrontados com a realidade experenciada no município a partir da consulta ao plano (PMIGRS, 2016). Para aumentar a eficiência das unidades, a discussão é recorrente: é necessário que a população segregue corretamente na fonte geradora e que o poder público invista em programas de educação ambiental e viabilize a coleta seletiva em termos de apoio técnico e financeiro.

Os problemas que acometem e inviabilizam o exercício do associativismo e do cooperativismo de catadores em Criciúma estão relacionados, basicamente, à inexistência de apoio por parte da gestão pública municipal. O funcionamento das unidades de triagem aquém de sua capacidade produtiva se dá tanto pelas péssimas condições de infraestrutura quanto pela falta de programas efetivos e contínuos de educação ambiental. Consequentemente à baixa sensibilização e desmotivação da população, tem-se uma redução na quantidade e na qualidade dos materiais destinados à coleta seletiva, e o principal efeito é o ganho reduzido dos catadores. 
Globalmente, as possibilidades de reciclagem dos resíduos e a consequente preservação dos ecossistemas do planeta são amplas, mas essa preservação precisa estar acompanhada de políticas públicas sociais, principalmente em relação aos países periféricos, onde há grande exclusão social e as economias não contam com o necessário desenvolvimento tecnológico. Diante desse contexto, é importante destacar a relevância dos catadores, bem como das cooperativas de reciclagem existentes no município e seu papel imprescindível para a economia do município.

Ademais, os empreendimentos solidários possuem grande importância social e econômica, pois se apresentam como uma forma de potencializar seus rendimentos e garantir seus direitos sociais de catadores. O cenário atual, no entanto, mostra que esses sujeitos não possuem incentivos para a realização da coleta seletiva, pois não são os principais responsáveis por essa atividade nos municípios, mas sim as empresas contratadas pelas prefeituras, sendo que, na região Sul do país, esse cenário é mais evidente. Nesse sentido, pode-se incluir que o estímulo da Política Nacional dos Resíduos Sólidos (BRASIL, 2010) à criação e ao desenvolvimento dessas organizações não vem sendo suficiente para que ocorra uma transformação do cenário nacional, regional e municipal em prol da inclusão social destes trabalhadores.

\section{REFERÊNCIAS}

ABRELPE - ASSOCIAÇÃO BRASILEIRA DE EMPRESAS DE LIMPEZA PÚBLICA E RESÍDUOS ESPECIAIS. Panorama dos Resíduos Sólidos no Brasil 2015. Disponível em: <http://www.abrelpe.org.br/panorama_apresentacao. cfm>. Acesso em: 20 jul. 2017.

ASSUNÇÃO, V. K. de; SOUZA, V. de O. de; GUADAGNIN, M. R; NUNES, L. Precarização do Trabalho e Injustiça Ambiental: Estudo de Caso em uma Cooperativa de Catadores e Catadoras de Materiais Recicláveis no 
Município de Criciúma (SC). In: Encontro Nacional da ANPPAS, 2017. Natal (RN). Anais... 2017.

PNRS. Plano Nacional de Resíduos Sólidos BRASIL. Disponível em: <http://www.mma.gov.br/port/conama/reuniao/dir1529/PNRS consultaspublicas.pdf>. 2012. Acesso em: 18 ago. 2017.

BRASIL. Lei n. 12.305: Institui a Política Nacional de Resíduos Sólidos; altera a Lei no 9.605, de 12 de fevereiro de 1998; e dá outras providências. Brasília: Congresso Nacional, 2010.

CHIZZOTTI, Antonio. Pesquisa em ciências humanas e sociais. 3. ed. São Paulo: Cortez, 1991.

CONSONI, A. J; PERES, C. S; CASTRO, A. P. de. Origem e composição do lixo. In: D’ALMEIDA, M. L. O; VILHENA, A. (Coords.). Lixo Municipal: manual de gerenciamento integrado. 2. ed. São Paulo: Instituto de Pesquisas Tecnológicas (IPT), e Compromisso Empresarial para Reciclagem (CEMPRE), 2000. p. 29-40.

CRESWELL, John W. Projeto de pesquisa: métodos qualitativo, quantitativo e misto. 2. ed. Porto Alegre: Artmed, 2007. 248 p.

GIL, Antonio Carlos. Metodologia do ensino superior. 2. ed. São Paulo: Atlas, 1994. 112 p.

GIL, Antonio Carlos. Como elaborar projetos de pesquisa. São Paulo: Atlas, 2007. 175 p. 
IBGE. Instituto Brasileiro de Geografia Estatística. 2016. Disponível em: <https://cidades.ibge.gov.br/brasil/sc/criciuma/panorama>. Acesso em: 12 abr. 2017.

JARDIM, N. S. et al. Gerenciamento integrado de lixo municipal. In. D’ALMEIDA, Maria Luiza Otero de; VILHENA, André (Coords.). Lixo Municipal: manual de gerenciamento integrado. São Paulo: Instituto de Pesquisas Tecnológicas (IPT), e Compromisso Empresarial para Reciclagem (CEMPRE), 2000. p. 3-25.

LIMA, J. D. de. Gestão de resíduos sólidos urbanos no Brasil. Campina Grande-PB, ABES, 2001.

MAGERA, M. C. Software VERDES - Viabilidade Econômica de Reciclagem dos Resíduos Sólidos. Software, 2007.

MARTINHO, M. da G. M; GONÇALVES, M. G. P. Gestão de resíduos. Lisboa, Universidade12 Aberta, 2000. .

MIURA, P. O; SAWAIA, B. B.. Tornar-se Catador: sofrimento ético-político e potência de ação. Psicologia \& Sociedade, Belo Horizonte, v. 25, n. 2, 2013. p. 331-341.

MONTEIRO, J. H. P. et al. Manual de Gerenciamento Integrado de Resíduos Sólidos, Rio de Janeiro: IBAM, 2001.

MONTEIRO, T. C. N. (Coord.). Gestão Integrada de Resíduos Sólidos Municipais e Impacto Ambiental: Guia para Preparação, Avaliação e Gestão de Projetos de Resíduos Sólidos Residenciais. Rio de Janeiro: FIOCRUZ, 2001. 
PHILIPPI JUNIOR, A. Saneamento, saúde e ambiente: fundamentos para um desenvolvimento sustentável. Barueri, SP: Manole, 2005.

PMGIRSC. PLANO MUNICIPAL DE GESTÃO INTEGRADA DE RESÍDUOS SÓLIDOS DE CRICIÚMA. 2016. Disponível em: <http://www.camaracriciuma.sc.gov.br/upload/2016/10/18/PE048-16\%20PMGIRS\%20META_3_ Aspectos_Gerais_do_Planejamento_das_Acoes_Criciuma.pdf>. Acesso em: 18 ago. 2017.

SEBRAE. Serviço de Apoio à Micro e Pequenas Empresas de SC, 2013.

SNIS. Secretaria Nacional de Saneamento Ambiental Sistema Nacional de Informações sobre Saneamento: diagnóstico do manejo de resíduos sólidos urbanos - 2015. Brasília: MCIDADES.SNSA, 2015.

SANTA CATARINA. Plano Diretor para a gestão e tratamento de resíduos sólidos urbanos do Estado de Santa Catarina, 2014.

VILHENA, A.; D ALMEIDA, M. L. O. Segregação de materiais In: D’ALMEIDA, M. L. O; VILHENA, A. (Coords.). Lixo Municipal: manual de gerenciamento integrado. 2. ed. São Paulo: Instituo de Pesquisas Tecnológicas - IPT/ Compromisso Empresarial para Reciclagem - CEMPRE, 2000. p. 81-89. 